\title{
Modelling the Income Distributions in the Czech Republic since 1992
}

\author{
Diana Bílková and Ivana Malá \\ University of Economics, Prague
}

\begin{abstract}
The goal of this article is to study incomes in the Czech Republic and their development since 1992. The net annual per capita income of Czech households is analysed for all households and their respective subpopulations. Data from the microcensus 1992, 1996, 2002, and EU-SILC 2005-2008 surveys carried out by the Czech Statistical Office are used. The subpopulations are defined by a household's location (Bohemia or Moravia), and education and age of the head of the household in order to compare the distributions of the income in Bohemia and Moravia and to quantify the impact of education and age on incomes. The three-parameter lognormal distribution is chosen as a probability distribution to model the per capita income distribution for the whole population and for subpopulations. To estimate the unknown parameters, the maximum likelihood method and that of L-moments are employed. The medians of equalised incomes are given for the EU members and the average growth in the 2004-2007 period is compared. For the Czech Republic, a comparison of the medians of per capita and equivalised income is made.
\end{abstract}

Zusammenfassung: Das Ziel dieses Artikels ist die Untersuchung des Einkommens in der Tschechischen Republik und dessen Entwicklung seit 1992. Das jährliche Nettoeinkommen tschechischer Haushalte wird für sämtliche Haushalte und einige Subpopulationen analysiert. Verwendet wurden Daten aus dem Mikrocensus 1992, 1996, 2002 und EU-SILC 2005-2008, die das Tschechische Statistikamt durchführt. Die Subpopulationen sind durch Standort des Haushalts (Böhmen oder Mähren), Ausbildung und Alter des Familienvorstands definiert, mit dem Ziel, die Einkommensverteilung in Böhmen und Mähren zu vergleichen und den Einfluss von Ausbildung und Alters auf das Einkommen zu quantifizieren. Die Verteilung des Pro-Kopf-Einkommens der Gesamtpopulation und von Subpopulationen wird durch die dreiparametrige Lognormalverteilung modelliert. Um die unbekannten Parameter zu schätzen, wurde die Maximum-Likelihood und die L-Momenten Methode angewandt. Das Medianäquivalenzeinkommen für EU Mitglieder und das Durchschnittswachstum 2004-2007 wird verglichen. Für die Tschechische Republik wird ein Vergleich der Mediane des Haushaltseinkommens und des Equivalenzeinkommen gemacht.

Keywords: Lognormal Distribution, Maximum Likelihood Estimation, LMoment Estimation.

\section{Introduction}

Wages and incomes of the population are in the centre of interest of economists in all developed countries of the world as there is a constant endeavor for objective answers to 
questions relating to the standard of living. Income models (and characteristics derived from them) can be used, apart from quality of life research, for making an inter-regional or international comparison of standards of living.

Not only knowledge of the overall income distribution over the given period and country, but also income distributions amongst particular subgroups of people are worthwhile. These distributions can be used in an analysis of income differentiation or income inequalities in society. Knowledge of income distributions can also be used for other purposes. It refers to process improvements relevant to other statistical variables correlating with income. We can give examples of household expenses and facilities, time utilization, purchasing purposes as well as various positions within the scope of sociological research. Having in mind all the above mentioned applications of income distribution analysis, we work with mass quantitative or qualitative observations.

In investigating income level and differentiation, indicators of income characteristics (such as average, median, standard deviation etc.) - categorized according to the sector of economy, gender, education, age and other criteria - are useful, but more detailed knowledge of the frequency distribution of income can be beneficial in the analysis.

Within the scope of this research, data provided by the Czech Statistical Office are used. These sets of data come from microcensus 1992, 1996 and 2002 and EU-SILC 2005-2008 (these surveys include data about incomes in 2004-2007). The first sample from 1992 is part of the survey that covered the Czech and Slovak Federal Republic. This federal state split into two parts: the Czech Republic and the Slovak Republic on January 1 st, 1993.

The analysis employs annual net nominal per capita income of Czech households in Czech crowns (CZK). The sample units are represented by the households whose heads are categorized according to education or age, respectively. Subpopulations in this paper are defined by a household's location (in the historical lands of Bohemia and Moravia), education (four levels) and age (10-year-long intervals) of the head of household, respectively.

In order to compare the development of incomes in households in the Czech Republic and in Europe, the medians of equalized (not per capita) incomes from European Union members (data from Eurostat) for 2004-2007 are shown.

In probability modelling, when the analysed income distribution is described by a probability model, a suitable probability distribution must be fitted and its unknown parameters have to be estimated. The choice of a proper distribution is the first step in a successful analysis. If the above choice is inappropriate, misleading results can be obtained. In this text, the three-parameter lognormal distribution is used. The appropriateness of this choice has been widely discussed in the literature from both theoretical and empirical point of view (see Johnson, Kotz, and Balakrishan, 1994; Kleiber and Kotz, 2003). As for the data for the Czech Republic, the fit of this distribution can be found in Bartošová (2006), Bartošová and Bína (2009) or Bílková (2008). A more detailed description with the use of a finite mixture of lognormal distributions is used for the Czech Republic in Pavelka (2009), for the United Kingdom in Flachaire and Nunez (2007). A variety of other probability distributions (sometimes called income distributions) is often encountered in the literature dealing with the topic. The generalized lambda distribution was used for incomes in the Czech Republic in Pacáková and Sipková (2007). The Dagum 
distribution is frequently used with good results. Loglogistic, generalized beta and Pareto distributions (for high incomes) are also successfully used in numerous resources dealing with the issue of wages or incomes (Dagum, 1990, 1997; McDonald, 1984; Parker, 1997; Kleiber and Kotz, 2003).

For an estimation of unknown parameters, the maximum likelihood method is usually employed, maximizing the logarithm of a likelihood function with respect to unknown parameters (a numerical procedure has to be applied as no closed formulas are known for estimators). In this paper, the results of this widespread estimation method are compared with those obtained from the use of so-called L-moments. L-moments and their use for the estimation of unknown parameters are briefly introduced. The differences between estimates (and quantities derived from these fits) detected by both methods are shown in Figures 5 to 7 and commented on in the text.

\section{Methodology}

\subsection{Three-Parameter Lognormal Distribution}

To model the distribution of annual net income per capita we use the three-parameter lognormal distribution with unknown parameters $\mu, \sigma$ and $\theta$. These parameters have a simple meaning, as the distribution and their values can be easily interpreted. If a random variable $X$ has a three-parameter lognormal distribution, $\operatorname{LN}\left(\mu, \sigma^{2}, \theta\right)$, then a variable $\log (X-\theta)$ has a normal distribution with expectation $\mu$ and variance $\sigma^{2}$. The parameter $\theta$ is the theoretical minimal value of $X$. The distribution is described by the probability density function

$$
f\left(x ; \mu, \sigma^{2}, \theta\right)=\frac{1}{\sqrt{2 \pi} \sigma(x-\theta)} \exp \left\{-\frac{(\log (x-\theta)-\mu)^{2}}{2 \sigma^{2}}\right\}, \quad x>\theta,
$$

where $\mu, \theta \in \mathbb{R}$ and $\sigma^{2}>0$.

The corresponding cumulative distribution function (cdf) can be written as

$$
F\left(x ; \mu, \sigma^{2}, \theta\right)= \begin{cases}0 & x \leq \theta \\ \Phi\left(\frac{\log (x-\theta)-\mu}{\sigma}\right) & x>\theta\end{cases}
$$

where $\Phi(\cdot)$ denotes the cdf of a standard normal distribution. In the text we use the first common and second central moment of the distribution given by

$$
\mathrm{E}(X)=\theta+e^{\mu+\sigma^{2}}, \quad \operatorname{var}(X)=e^{2 \mu+\sigma^{2}}\left(e^{\sigma^{2}}-1\right) .
$$

The quantiles are

$$
x_{p}=\theta+\exp \left(\mu+\sigma u_{p}\right), \quad 0<p<1 .
$$

Here $x_{p}$ denotes a $100 p \%$ quantile of the lognormal distribution, and $u_{p}$ is the $100 p \%$ quantile of a standard normal distribution. 


\subsection{Methods of Estimation}

Parameters of the lognormal distribution are estimated with the use of the maximum likelihood method and that of L-moments. Suppose that $X$ is a random variable and the sample of $n$ observations from the distribution of $X$ is $X_{1}, \ldots, X_{n}$. The ordered sample is denoted by $X_{1: n}, \ldots, X_{n: n}$ with $X_{1: n} \leq \cdots \leq X_{n: n}$.

Maximum likelihood estimates $\hat{\mu}, \hat{\sigma}$, and $\hat{\theta}$ of the three unknown parameters in (1) were calculated by a numerical optimization procedure (see Cohen and Whitten, 1980) where the logarithm of the likelihood function based on (1) is maximized with respect to the parameters.

The method of L-moments is less known and part of the estimation is briefly described. The estimates of the unknown parameters $\mu, \sigma$, and $\theta$ obtained by this method are denoted by $\tilde{\mu}, \tilde{\sigma}$, and $\tilde{\theta}$. Theoretical values of the L-moments are linear combinations (L stands for "linear") of the expectations of the order statistics. By ordering we mean ordering of the sample elements from the smallest to the largest value. The $k$-th population L-moment $\lambda_{k}$, for $k=1, \ldots, n$, is defined as

$$
\lambda_{k}=\frac{1}{k} \sum_{j=0}^{k-1}(-1)^{j}\left(\begin{array}{c}
k-1 \\
j
\end{array}\right) \mathrm{E}\left(X_{k-j: n}\right),
$$

where $\mathrm{E}\left(X_{j: n}\right)$ denotes the expectation of the $j$-th order statistic from an independent sample of size $n$. It can be seen from (3) that the first L-moment $\lambda_{1}$ is equal to the mean of $X$. It can be shown (Hosking, 1990) that if $\lambda_{1}$ is finite, all L-moments exist and are finite.

The sample $k$-th L-moment is the sample version of (3), i.e.

$$
l_{k}=\left(\begin{array}{l}
n \\
k
\end{array}\right)^{-1} \sum_{1 \leq i_{1}<\cdots<i_{k} \leq n} \frac{1}{k} \sum_{j=0}^{k-1}(-1)^{j}\left(\begin{array}{c}
k-1 \\
j
\end{array}\right) X_{i_{k}-j: n},
$$

where $i_{1}, \ldots, i_{k}$ and $X_{i_{1}}, \ldots, X_{i_{k}}$ are ordered subsamples of size $k$ from the ordered sample of the size $n\left(\left(\begin{array}{l}n \\ k\end{array}\right)\right.$ subsamples). Instead of formula (4), the sample L-moments can be evaluated with the use of a more convenient formula for computation (see Hosking, 1990, or Hosking and Wales, 1997) as

$$
l_{k}=\sum_{j=0}^{k-1}(-1)^{k-1-j}\left(\begin{array}{c}
k-1 \\
j
\end{array}\right)\left(\begin{array}{c}
k-1+j \\
j
\end{array}\right) b_{j}
$$

where

$$
b_{j}=\frac{1}{n} \sum_{i=j+1}^{n} \frac{(i-1)(i-2) \cdots(i-j)}{(n-1)(n-2) \cdots(n-j)} X_{i: n}, \quad j=0, \ldots, k-1 .
$$

In Hosking (1990) relations between the parameters $\mu, \sigma, \theta$ and the first three theoretical L-moments $\lambda_{1}, \lambda_{2}, \lambda_{3}$ are given and values of the L-moments are evaluated with the use of the distribution parameters. Moreover, the inverse relationship between the first three sample L-moments $l_{1}, l_{2}, l_{3}$ and the maximum likelihood estimates $\tilde{\mu}, \tilde{\sigma}, \tilde{\theta}$ are also derived 
in Hosking (1990). In the following, in order to estimate the parameters of lognormal distributions using L-moments, the first three sample L-moments are evaluated according to formula (5). Then estimates of the unknown parameters in the lognormal cdf are found as (Hosking, 1990)

$$
\begin{aligned}
\tilde{\sigma} & =0.999281 z-0.006118 z^{3}+0.000127 z^{5} \\
\tilde{\mu} & =\log \left(l_{2} /(2 \Phi(\tilde{\sigma} / \sqrt{2})-1)\right)-\tilde{\sigma}^{2} / 2 \\
\tilde{\theta} & =l_{1}-\exp \left(\tilde{\mu}+\tilde{\sigma}^{2} / 2\right)
\end{aligned}
$$

where

$$
z=\sqrt{\frac{8}{3}} \Phi^{-1}\left(\frac{1+t_{3}}{2}\right)=\sqrt{\frac{8}{3}} u_{\left(\frac{1+l_{3} / l_{2}}{2}\right)} .
$$

Here, $u_{p}$ denotes the $100 p \%$ quantile of the standard normal distribution and $t_{3}=l_{3} / l_{2}$ is the sample third L-moment ratio. More about L-moments can be found, for example, in Smithers and Schulze (2001) or Kyselý and Picek (2007). All computations (and numerical method applications) were made in Excel and R 2.13.1. To describe the fitted distribution, estimates of the parameters are plugged into the above results.

\subsection{Characteristics of Differentiation}

There are various characteristics to describe the variability of incomes (or differentiation of incomes) - variance, standard deviation, coefficient of variation or Gini index (Kleiber and Kotz, 2003). Here, only the standard deviation and a coefficient of variation is used. As L-moments are of interest, we give a few comments on the relationship between twoand three-parameter lognormal distribution and characteristics of differentiation.

If the two-parameter lognormal distribution is used, it is clear from (2) (if we take $\theta=0$ ) that the coefficient of variation depends only on the parameter $\sigma^{2}$ and equals $\sqrt{\exp \left(\sigma^{2}\right)-1}$. In various articles (Kleiber and Kotz, 2003), formulas for the Gini coefficient can be found in the form of $\operatorname{erf}(\sigma / 2)$, where erf is the error function, or equivalently as $2 \Phi(\sigma / \sqrt{2})-1$. Unfortunately, in the case of the three-parameter model this doesn't hold and both characteristics depend on all three parameters. For the coefficient of variation we have from (2)

$$
V=\frac{\exp \left(\mu+\sigma^{2} / 2\right) \sqrt{\exp \left(\sigma^{2}\right)-1}}{\theta+\exp \left(\mu+\sigma^{2} / 2\right)} .
$$

Formula (3) for $k=2$ can be rewritten as

$$
\lambda_{2}=\frac{1}{2} \mathrm{E}\left(X_{2: 2}-X_{2: 1}\right)=\frac{1}{2} \mathrm{E}\left(\left|X_{1}-X_{2}\right|\right)
$$

and we conclude that the Gini mean difference is $2 \lambda_{2}$ (see also Hosking, 1990) and the Gini coefficient can be evaluated as $\lambda_{2} / \lambda_{1}$. Moreover, with the use of Hosking's paper we obtain for the Gini coefficient $G$ of the three-parameter lognormal distribution the result

$$
G=\frac{\exp \left(\mu+\sigma^{2} / 2\right) \operatorname{erf}(\sigma / 2)}{\theta+\exp \left(\mu+\sigma^{2} / 2\right)} .
$$

Here, Gini coefficients are not included but from previous considerations the usefulness of L-moments in evaluating these characteristics is clear. 


\section{Data Analysis and Results}

\subsection{Per Capita Income in the Czech Republic}

In the paper, we use particular data about Czech households from microcensus (files for 1992, 1996, and 2002) and from the Living Conditions Survey, a national module of the European Union Statistics on Income and Living Conditions (EU-SILC), from 2005, 2006, 2007, and 2008. Net annual household income per capita (nominal income) is the analysed variable. These surveys were carried out by the Czech Statistical Office.

For the sake of completeness, we use data from the microcensus, focusing, however, on EU-SILC figures. The aim of the annual survey is to gather representative data on the income distribution for the whole population and for various household types, housing conditions (housing quality and affordability), household durables, labour, financial and health conditions of adults living in private households (CZSO, Czech Statistical Office). The total net income of a household is the sum of all monetary and non-monetary earnings of all members of the household after tax and deductions. EU-SILC data are collected by means of questionnaires with different units of reference - dwelling unit, household and personal questionnaires (for all members over 16 years of age). Social benefits targeted at particular households, annuity income and the value of goods produced directly by the household through either private or professional activity are covered by a household questionnaire. Income from employment (permanent and temporary jobs), sickness, oldage, unemployment and social benefits claimed by individuals as well as other incomes (such as capital income, sales of property, insurance claims, etc.) are recorded in personal questionnaire forms.

Data for various types of income of Czech households were collected together with other characteristics such as the status of the head of household, the number of employed household members and dependent children, household type, the age and education of the head of household, the size of municipality and region, etc. Marriages with or without children are always headed by men, regardless of their economic activities. In lone-parent families or non-family households, the primary criterion for determination of the head of household status was economic activity and the secondary criterion was the income of household members (CZSO). For our analysis, net income per capita was evaluated as the ratio of the total annual net income of a household to the number of household members. This variable is the ratio of two random variables, the value having been evaluated for each household in the sample and data being treated as a random sample (not stratified the way it was). Furthermore, the households were divided into groups according to their location (Bohemia, Moravia), the household head's education (primary, secondary, complete secondary, and tertiary education) and age (grouped into ten-year intervals: under $30,30-40,40-50,50-60$, over 60). In the following text, "income" is used instead of "annual net income per capita in CZK".

Sample characteristics of all the analysed samples are given in Table 1. There are very different sample sizes (from 4,352 households in 2006 to 28,148 households in 1996), precise numbers of households in subgroups being displayed in Table 2. We can see from the table that almost all samples are large, the smallest value being 118 household heads with complete secondary education in 2004. 
Table 1: Sample characteristics, inflation rate and CZK/EUR exchange rate.

\begin{tabular}{lrrrrrrr}
\hline Year & 1992 & 1996 & 2002 & 2004 & 2005 & 2006 & 2007 \\
\hline Sample size & 16,233 & 28,148 & 7,973 & 4,351 & 7,483 & 9,675 & 11,294 \\
\hline Mean & 35,247 & 68,286 & 105,030 & 111,024 & 114,945 & 123,806 & 132,877 \\
Median & 31,000 & 57,700 & 89,204 & 97,050 & 100,640 & 108,744 & 117,497 \\
\hline Standard deviation & 19,364 & 51,102 & 83,598 & 77,676 & 74,503 & 74,578 & 73,982 \\
Coeff. of variation & 0.549 & 0.748 & 0.795 & 0.699 & 0.648 & 0.602 & 0.556 \\
\hline Coeff. of skewness & 7.8 & 17.6 & 17.1 & 14.9 & 10.3 & 7.7 & 6.9 \\
\hline $1 \%$ quantile & 13,521 & 21,246 & 31,201 & 29,909 & 33,429 & 35,383 & 40,795 \\
$5 \%$ quantile & 18,498 & 32,100 & 45,777 & 47,657 & 49,914 & 55,914 & 63,888 \\
$10 \%$ quantile & 21,292 & 37,935 & 54,366 & 58,120 & 60,832 & 68,147 & 76,571 \\
$25 \%$ quantile & 25,900 & 47,550 & 73,464 & 79,600 & 82,998 & 90,000 & 97,160 \\
$75 \%$ quantile & 39,298 & 76,550 & 115,966 & 124,068 & 128,000 & 138,000 & 148,937 \\
$90 \%$ quantile & 51,977 & 105,100 & 163,281 & 171,833 & 174,904 & 189,505 & 202,327 \\
$95 \%$ quantile & 63,864 & 130,138 & 206,601 & 215,307 & 217,366 & 231,913 & 246,600 \\
$99 \%$ quantile & 102,627 & 223,642 & 333,915 & 343,287 & 368,429 & 372,504 & 391,094 \\
\hline Inflation rate & - & - & 1.358 & 1.029 & 1.019 & 1.025 & 1.028 \\
Exchange rate & - & - & 30.812 & 31.904 & 29.784 & 28.343 & 26.300 \\
\hline
\end{tabular}

Source: own computations, $\mathrm{CZSO}$ and $\mathrm{CNB}$

In the analysed period the level of incomes increased markedly as both characteristics of location (the arithmetic average and the median in CZK) increased in time (mean income from 35,000 CZK in 1992 to almost 133,000 CZK in 2008, the median from 31,000 CZK to more than $117,000 \mathrm{CZK}$ ). Table 1 also offers a review of income differentiation. The characteristics of absolute variability (standard deviation in CZK) show a rising trend at first (the period between 1992 and 2002) and later fluctuate around a constant value. The characteristic of relative variability (the coefficient of variation in \%) also increases between 1992 and 2002, but in the following years it shows a decreasing trend. A certain diversity in the light of income distribution skewness is further palpable from Table 1. The positive skewness of distribution of net per capita household incomes over all the analysed periods is shown. From this it follows that lower per capita incomes predominate in comparison with higher incomes in the given sets of data. It is a typical situation not only for income distributions, but also for wage distributions. In the last two rows of Table 1, the inflation rate and average rate of CZK/EUR are shown. The median value of per capita income in CZK increased from 2004 to 2007 by $21.1 \%$, the mean value by $19.7 \%$ and inflation was $7.4 \%$. If we use the exchange rate from Table 1 , the increase was $46.8 \%$ for the median and $45 \%$ for the mean. It reflects the strengthening of the Czech crown that is obvious from Table 1.

The development of chosen sample percentiles is shown in Figure 1. The above mentioned positive skewness is obvious from the gap between the graph lines. Lower quartile (under the median) curves are denser; those above the median are rarer. The line that separates $1 \%$ of the highest incomes (99\% quantile) is markedly distant from the others.

Moreover, the interval in which $50 \%$ of middle per capita incomes occur can be 
Table 2: Sample sizes of the analysed samples and subsamples.

\begin{tabular}{llrrrrrrr}
\hline & & \multicolumn{7}{c}{ Year } \\
\cline { 2 - 8 } & Set & 1992 & 1996 & 2002 & 2004 & 2005 & 2006 & 2007 \\
\hline Land & Czech Republic & 16,233 & 28,148 & 7,973 & 4,351 & 7,483 & 9,675 & 11,294 \\
& Bohemia & 9,923 & 22,684 & 5,520 & 2,775 & 4,692 & 6,086 & 7,074 \\
& Moravia & 6,310 & 5,464 & 2,453 & 1,576 & 2,791 & 3,589 & 4,220 \\
\hline \multirow{2}{*}{ Education } & Primary & 9,302 & 15,891 & 3,480 & 553 & 940 & 1,183 & 1,385 \\
& Secondary & 4,646 & 3,172 & 2,493 & 3,186 & 5,460 & 7,168 & 8,371 \\
& Complete secondary & 1,951 & 6,356 & 1,129 & 118 & 282 & 266 & 319 \\
& Tertiary & 334 & 2,729 & 871 & 494 & 801 & 1,058 & 1,219 \\
\hline Age & $\leq 29$ & 1,680 & 2,809 & 817 & 413 & 627 & 649 & 827 \\
& $30-39$ & 3,035 & 4,718 & 1,398 & 716 & 1,247 & 1,620 & 1,655 \\
& $40-49$ & 3,829 & 6,348 & 1,446 & 738 & 1,249 & 1,609 & 1,863 \\
& $50-59$ & 2,621 & 5,216 & 1,642 & 919 & 1,581 & 2,051 & 2,391 \\
& $\geq 60$ & 5,068 & 9,057 & 2,670 & 1,565 & 2,779 & 3,746 & 4,558 \\
\hline
\end{tabular}

specified from Table 1. For example, in $199250 \%$ of middle per capita incomes occurred in the interval from 25,900 CZK to 39,298 CZK (the interval length of 13,400 CZK), while in $200750 \%$ of per capita incomes occurred in the interval from 97,160 CZK to 148,937 CZK (the length of more than 51 thousand CZK). This length of the interval of fifty percent of medium incomes (interquartile range) is gradually gaping (see also Figure 1 and the three lines in the middle of the figure - for lower, median and upper quartile).

The first decile can be used as an upper bound for low incomes; the ninth decile, on the contrary, is used in the text as a lower bound of high incomes. In 1992 ten per cent of households had their income lower than or equal to 21,292 CZK. This bound increased gradually to the amount of 76,571 CZK in 2007. In the light of determination of 10 percent of the highest per capita incomes, in 1992 ten \% of the highest incomes were equal to or higher than 51,977 CZK. This bound also increased gradually in time to the amount of 202,327 CZK in 2007. Marginal percentiles (1\% and 99\%) are used for the characterization of minimum and maximum incomes. In the interval given by these values, there are $98 \%$ of middle incomes and only $1 \%$ of the lowest and $1 \%$ of the highest incomes are excluded. The development of the above mentioned quantities is noticeable in Figure 1.

The median is frequently used as a characteristic of the location of the sample instead of the mean in case of a skewed distribution. As a supplement to Figure 1, sample medians are shown for subpopulations defined by a household's location (Figure 2) and the education and age of the head of household (Figures 3 and 4 respectively). The line for the whole sample is shown in each figure in order to indicate a relative position of subgroups towards the whole sample. The values of the medians are given in Table 8. No obvious differences in the level of per capita incomes between the populations of Bohemia and Moravia are noticeable in Figure 2, although the level of incomes is a little higher in Bohemia compared to Moravia during the analysed period. The level of income has a 


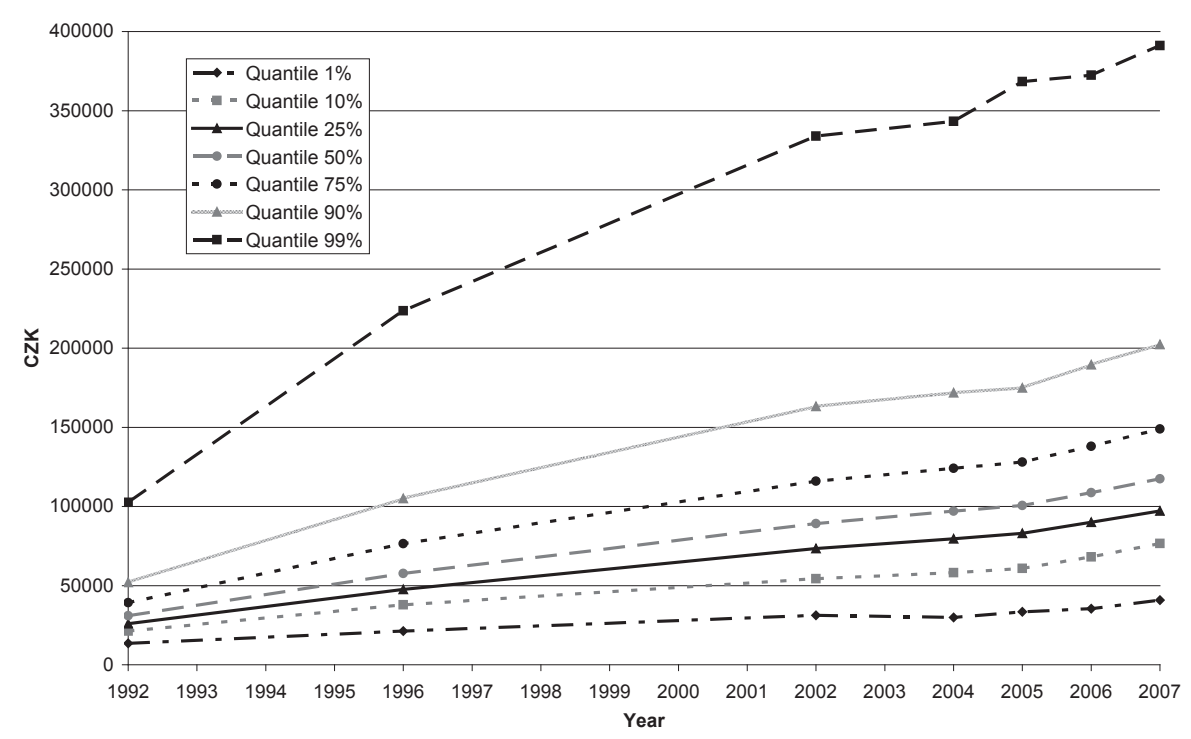

Figure 1: Sample percentiles $(1 \%, 10 \%, 25 \%, 50 \%, 75 \%, 90 \%, 99 \%)$ in CZK.

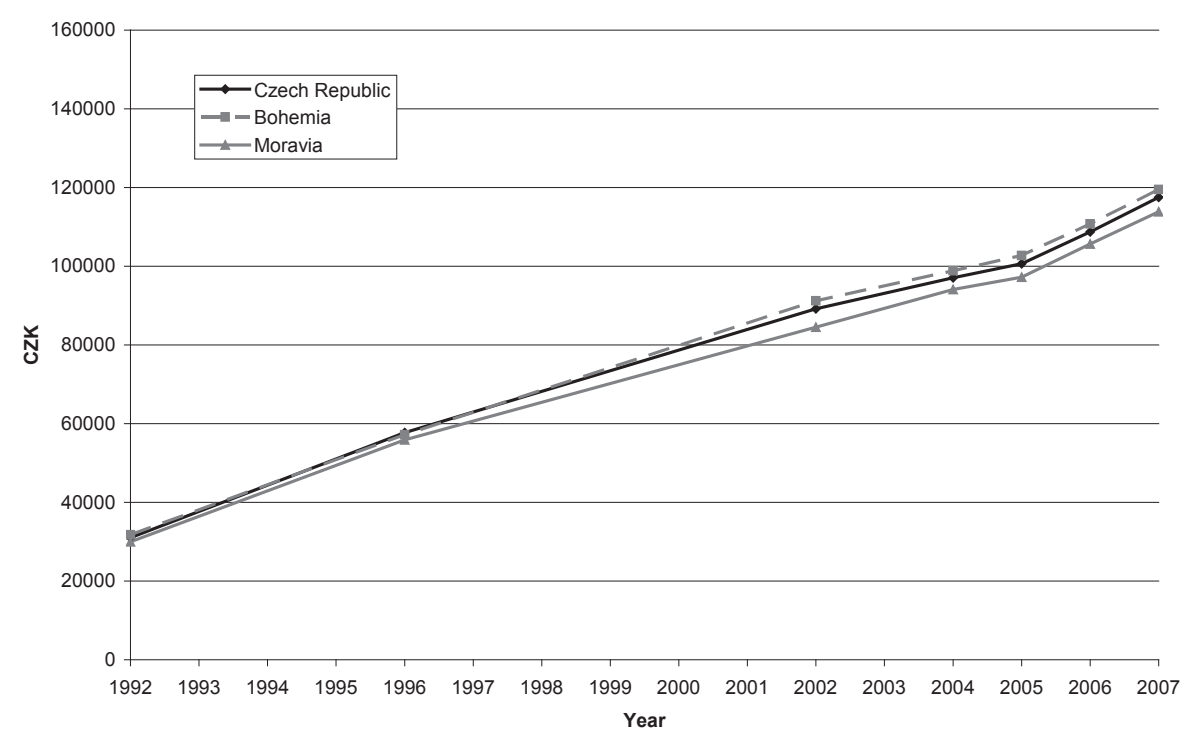

Figure 2: Sample medians of annual net per capita income (historical lands).

markedly increasing trend over the whole period in both historical lands (with the exception of 2004-2005) and the dynamics of this upward trend deserve a thorough analysis If the analysed 16-year time interval is divided into three periods, 1992-2002, 2002-2004 and 2004-2007, the development can be characterized by means of the annual difference in the median income. In the first period the median income increased by $11.1 \%$ a year on average in Bohemia (from 31,779 CZK in 1992 to 91,200 CZK in 2002) and by $10.9 \%$ in Moravia (from 29,994 CZK in 1992 to 84,514 CZK in 2002). During the next period the rate of growth falls slightly, but it is necessary to have in mind that only two observations (the initial level in 2002 and the ending value in 2004) are registered. The median per 


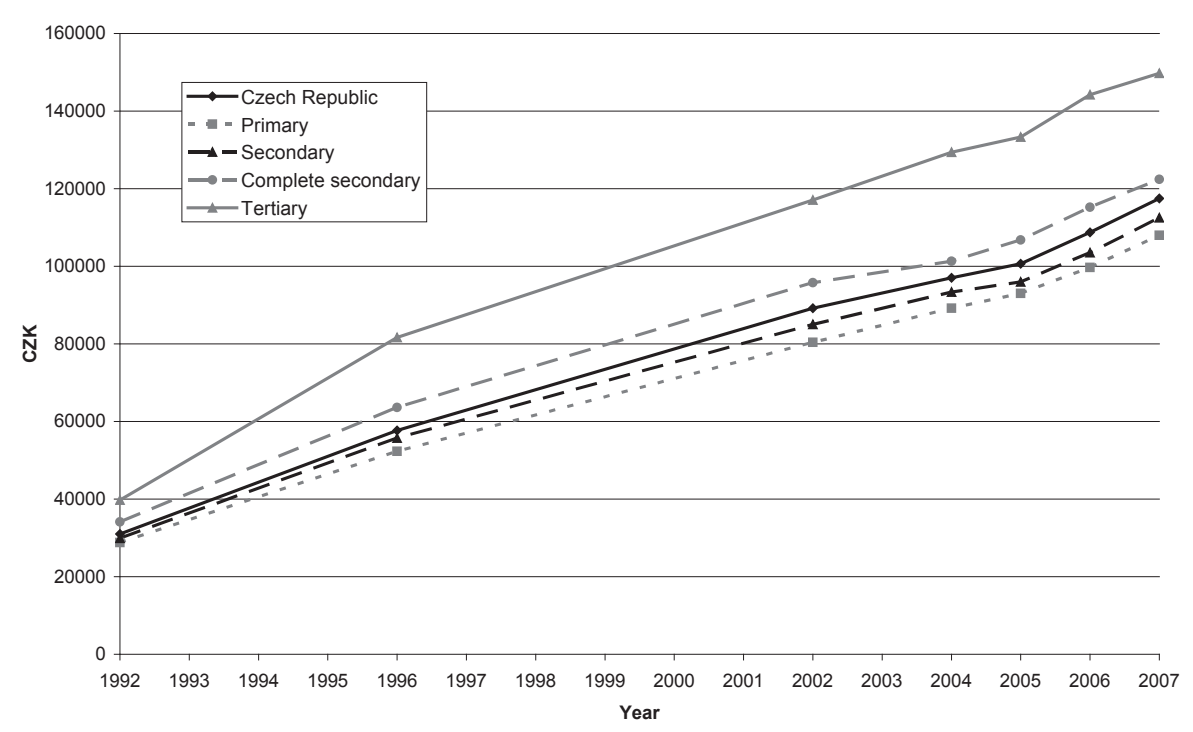

Figure 3: Sample medians of net per capita income (education of the head of household).

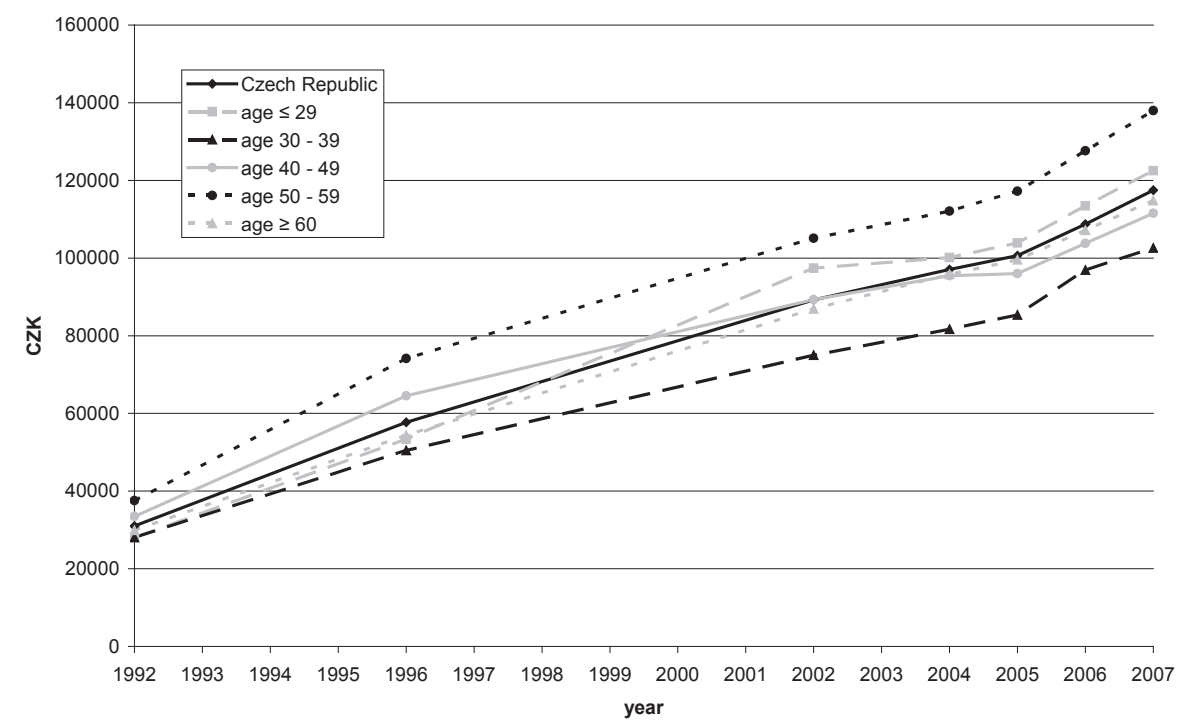

Figure 4: Sample medians of annual net income per capita (age of the head of household).

capita income in Bohemia grew by $4.1 \%$ a year on average (from 91,200 CZK in 2002 to $98,861 \mathrm{CZK}$ in 2004) while in Moravia it rose by $5.5 \%$ on average (from $84,514 \mathrm{CZK}$ in 2002 to $94,092 \mathrm{CZK}$ in 2004). It means that in this period the rate of growth was higher in Moravia than in Bohemia. During the last period the growth rate of net annual per capita incomes rises again, the median of incomes increasing by $6.5 \%$ a year on average in Bohemia (from 98,861 CZK in 2004 to 119,508 CZK in 2007) while in Moravia by $6.6 \%$ (from 94,092 CZK in 2004 to 113,826 CZK in 2007).

In Figure 2, the positive impact of education is obvious. We would like to note that only education of the head of household is taken into account, other household members' 
Table 3: Estimates of parameters for the whole samples, $\chi^{2}$ statistics with $27 \mathrm{df}$.

\begin{tabular}{lcrrrrrrr}
\hline \multirow{2}{*}{ Method } & & & & \multicolumn{5}{c}{ Year } \\
Maximum & $\mu$ & 1992 & 1996 & 2002 & 2004 & 2005 & 2006 & 2007 \\
likelihood & $\sigma$ & 0.390 & 10.995 & 11.438 & 11.503 & 11.542 & 11.623 & 11.703 \\
& $\theta$ & -0.3 & 52.2 & 73.5 & 7.6 & -8.8 & -42.3 & -171.2 \\
& $\chi^{2}$ & 1,227 & 2,197 & 1,060 & 524 & 995 & 1,067 & 1,199 \\
\hline L-moments & $\mu$ & 9.696 & 10.343 & 10.819 & 11.028 & 11.040 & 11.112 & 11.163 \\
& $\sigma$ & 0.700 & 0.545 & 0.773 & 0.675 & 0.677 & 0.440 & 0.654 \\
& $\theta$ & 14,491 & 25,362 & 37,685 & 33,738 & 36,606 & 40,327 & 45,634 \\
& $\chi^{2}$ & 811 & 1,742 & 1,535 & 866 & 999 & 959 & 1,220 \\
\hline & & & & & & & \multicolumn{2}{c}{ Source: own computations }
\end{tabular}

education (that of a spouse in particular) is not reflected in the analysis. The median per capita income in 2007 for the head of household with tertiary education $(149,751 \mathrm{CZK})$ is 122 percent of the median income for complete secondary education, the respective medians being 122,398 CZK, 112,508 CZK and 107,986 CZK for secondary complete, secondary incomplete and primary education.

It is evident from Figure 4 that the net per capita income of a household depends on the age of its head. The level of income gradually rises during the whole survey period. The level of per capita income of the households whose head is between 30 and 40 years of age is lower than that of the households whose head is 30 years old or younger. The reason evidently lies in the fact that young people up to 30 get ahead in career and start a family later; at that time their income decreased markedly. The level of income rises with age up to 50-60 years which is the last age group formed by the majority of employed people. Most people in the group over 60 retire and the income goes down again. Households with the head in the 50-60 age group have the highest per capita income, whereas members of the 30-40 year of age group have the lowest median of per capita income. Some of these observations are surprising, as we would expect a better position of households with younger male heads. This is the reason for analysing equalised incomes instead of per capita incomes. Equalised income takes into account potential expenditure sharing in households, especially in those with children. If we use per capita income, households with children (usually with $20-40$ or 50-year-old heads) are disadvantaged when we put weight 1 to each member of a household. If equalised incomes are used, weights depend on the structure of a household and weight 1 is assigned only to the head of household.

The three-parameter lognormal distribution was fitted into the sets of data described above. Estimates of three parameters of the lognormal distribution for the whole sample for each year obtained by both methods of estimation mentioned above are given in Table 3. Differences between estimates, especially to estimate the shift parameter $\theta$, are apparent in the table. It is clear that even in the case of large samples, the estimates of parameters depend strongly on the method of estimation. According to Figure 5, however, characteristics of the level evaluated on the basis of these estimates are similar.

From our analysis, we conclude that estimation errors (not given in the text) are rather high when the shift parameter $\theta$ is estimated in comparison with other two parameters. 


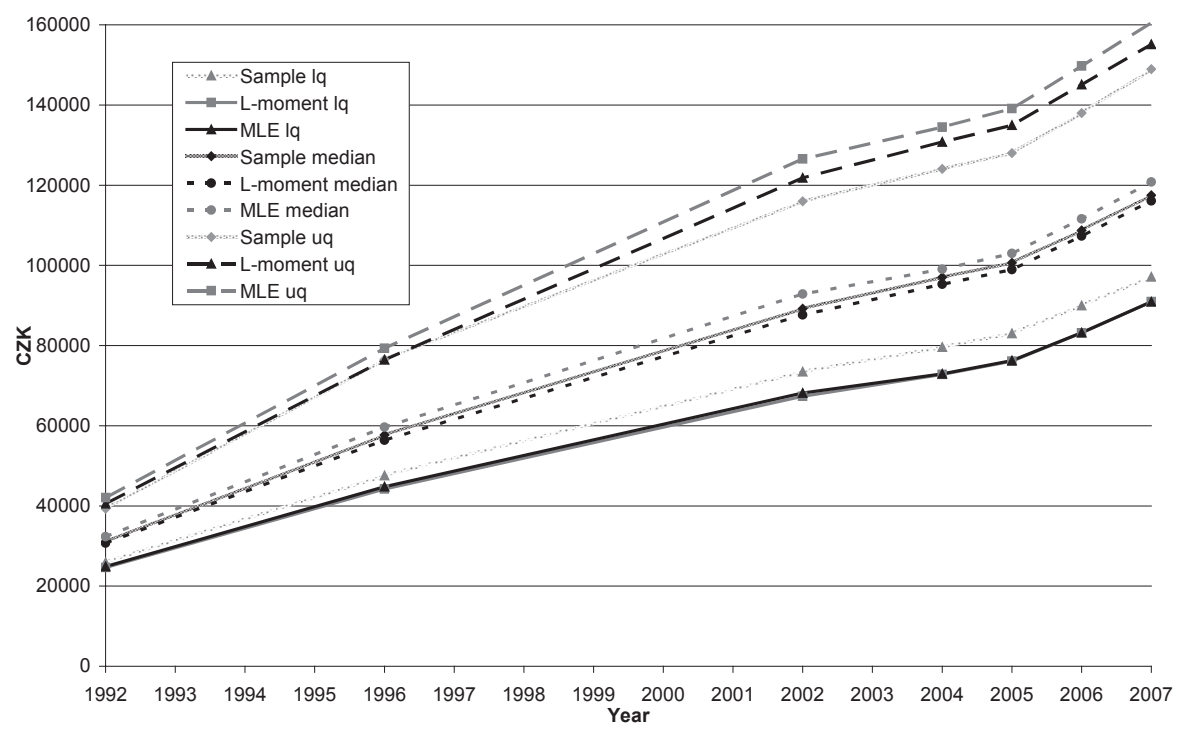

Figure 5: Sample and estimated quartiles (lower quartile, median, upper quartile).

Very different values of the parameter $\theta$ are shown in Table 3. The values of theta for maximum likelihood estimates are even negative and estimates via L-moments are greater than minimal incomes, coinciding roughly with the third percentile. Because of a very close contact of the lower tail of the lognormal density curve with the horizontal axis, the negative parameter theta does not seem to be a problem for a good fit of the model. Due to its estimates being negative, however, the value of theta has no interpretation. The estimates of the parameter $\mu$ are smaller in the case of maximum likelihood estimation; both methods point to an increase of these parameters in time. The variance parameter $\sigma^{2}$ is remarkably greater for L-moments estimation.

The fitted models may be compared with the use of various techniques; in this text, the $\chi^{2}$ statistic of a goodness-of-fit test was employed. Because of the time development of income level, different evaluation intervals (31 in each year) were used for different values of income. The $\chi^{2}$ statistic depends strongly on the choice of intervals for small values of income because of very different estimates of the shift parameter $\theta$. No method of estimation seems to be superior for all analysed years. It coincides with the literature, as for large samples maximum likelihood estimates have an optimal theoretical (asymptotic) property. Estimates with the use of L-moments are sometimes more efficient than maximum likelihood estimates, see Hosking (1990). For all years $p$-values for the goodness-of-fit test equal zero, so they are not given in Table 3.

In Figures 6 and 7, the estimated lognormal densities are shown. Estimated modes are not given in the text, but from these two figures the development of this (estimated) characteristic of the income level is obvious. The modes shift from the left (1992) to the right (2007) and values of densities in the mode decrease with time. The curves are similar in their shapes, but as the scale of both figures is the same, we observe different values of estimated densities. 


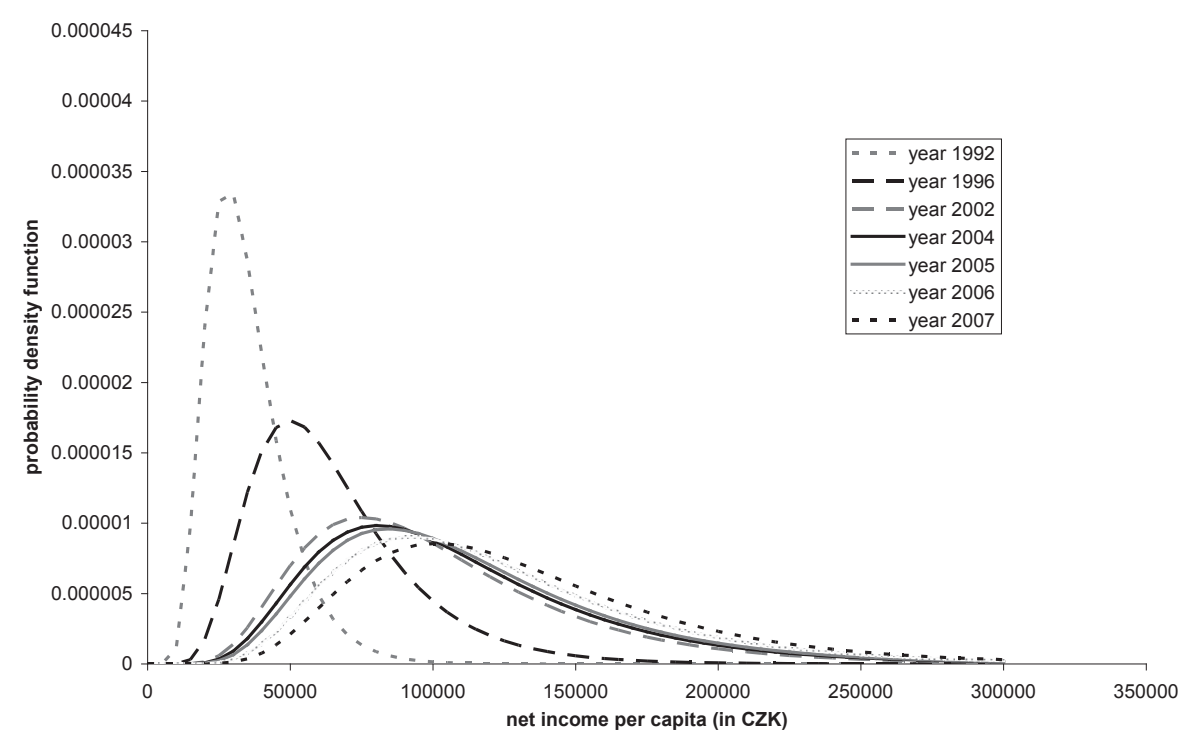

Figure 6: Estimated lognormal densities for annual net per capita income (CZK) for 1992, 1996, 2002, 2004-2007 (maximum likelihood method).

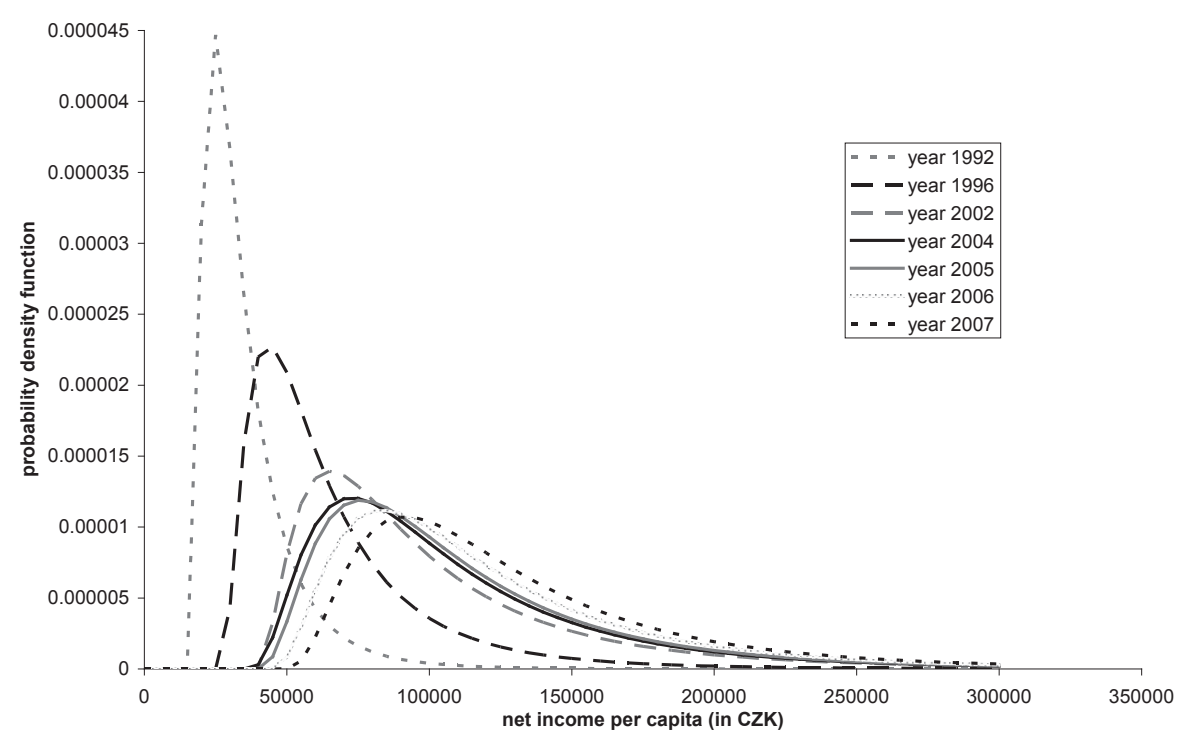

Figure 7: Estimated lognormal densities for annual net per capita income (CZK) (Lmoment method).

\subsection{Equivalised Income in the European Union}

This chapter offers a comparison of nominal income levels in the European Union countries (in EUR) between 2004 and 2007 (and a more recent value for 2009 in Figure 7). 
Table 4: Medians of equalised net annual income in 2004-2007 (in EUR).

\begin{tabular}{l|rrrr}
\hline & \multicolumn{4}{|c}{ Year } \\
Country & 2004 & 2005 & 2006 & 2007 \\
\hline EU (all 27 countries) & 12,975 & 13,188 & 13,900 & 14,598 \\
EU (15 old countries) & 15,465 & 15,575 & 16,545 & 17,282 \\
EU (12 new countries) & - & - & 3,255 & 3,868 \\
Austria & 18,001 & 17,854 & 18,156 & 19,011 \\
Belgium & 16,581 & 17,213 & 17,566 & 17,985 \\
Bulgaria & - & 1,383 & 1,481 & 2,171 \\
Cyprus & 13,157 & 14,536 & 16,014 & 16,765 \\
Czech Republic & 4,233 & 4,802 & 5,423 & 6,068 \\
Denmark & 22,124 & 22,663 & 23,341 & 24,161 \\
Estonia & 2,981 & 3,639 & 4,448 & 5,547 \\
Finland & 17,496 & 18,345 & 18,703 & 19,815 \\
France & 15,946 & 16,209 & 16,441 & 18,984 \\
Germany & 6,393 & 15,663 & 17,777 & 18,309 \\
Greece & 9,417 & 9,850 & 10,200 & 10,800 \\
Hungary & 3,447 & 3,850 & 3,936 & 4,400 \\
Ireland & 18,798 & 19,757 & 22,065 & 22,995 \\
Italy & 14,352 & 14,524 & 15,011 & 15,639 \\
Latvia & 2,204 & 2,534 & 3,350 & 4,832 \\
Lithuania & 2,058 & 2,534 & 3,276 & 4,169 \\
Luxembourg & 28,396 & 29,480 & 29,892 & 30,917 \\
Malta & 8,047 & 8,747 & 9,100 & 9,558 \\
Netherlands & 17,001 & 17,263 & 18,244 & 19,522 \\
Poland & 2,533 & 3,111 & 3,502 & 4,155 \\
Portugal & 7,195 & 7,311 & 7,573 & 8,143 \\
Spain & 10,600 & 11,480 & 12,038 & 12,950 \\
Romania & - & - & 1,657 & 1,953 \\
Slovenia & 8,797 & 9,317 & 9,907 & 10,893 \\
Slovakia & 2,830 & 3,313 & 3,972 & 4,792 \\
Sweden & 17,499 & 17,991 & 18,845 & 20,573 \\
United Kingdom & 18,540 & 19,512 & 21,014 & 18,923 \\
\hline & & & & Source: Eurostat
\end{tabular}

The income that is analysed here is not a net annual household income per capita as in Subsection 3.1, but the net annual household income per economic unit, or the equivalised income. In the EU methodology, the head of household's weight value is 1, other adult household members and children having weights of 0.5 and 0.3 respectively (an alternative weighing system is that of OECD). It means that a household with two parents and two children has 4 members (for per capita income evaluation $4 \times 1=4$ in the denominator) but only $2.1(=1+0.5+2 \times 0.3)$ when equalised income is evaluated. Even greater is the gap in the case of a household with a single parent and 3 children, where the number of members is 4 again, but the number of economic units is $1.9(=1+3 \times 0.3)$. As the total net income is the same for both the approaches (per capita and per economic 
Table 5: Average growth of the net annual equivalised income median in 2004-2007.

\begin{tabular}{|c|c|c|c|c|}
\hline Countries & EU 27 & EU 15 & EU 12 & Czech Republic \\
\hline $\begin{array}{l}\text { Average } \\
\text { growth rate }\end{array}$ & 1.040 & 1.038 & $1.188(2006-2007)$ & $\begin{array}{l}1.128(2004-2007) \\
1.119(2006-2007)\end{array}$ \\
\hline
\end{tabular}

Table 6: Average growth of the net annual income median in 2004-2007.

\begin{tabular}{|c|c|c|c|}
\hline \multicolumn{2}{|c|}{ EU 15} & \multicolumn{2}{|c|}{ EU 12} \\
\hline Country & $\begin{array}{l}\text { Average } \\
\text { growth rate }\end{array}$ & Country & $\begin{array}{l}\text { Average } \\
\text { growth rate }\end{array}$ \\
\hline Austria & 1.018 & Bulgaria & $1.253^{*}$ \\
\hline Belgium & 1.027 & Cyprus & 1.084 \\
\hline Denmark & 1.030 & Czech Republic & 1.128 \\
\hline Finland & 1.042 & Estonia & 1.230 \\
\hline France & 1.060 & Hungary & 1.085 \\
\hline Germany & 1.038 & Latvia & 1.299 \\
\hline Greece & 1.047 & Lithuania & 1.265 \\
\hline Ireland & 1.069 & Malta & 1.059 \\
\hline Italy & 1.029 & Poland & 1.179 \\
\hline Luxembourg & 1.029 & Romania & $1.179^{* *}$ \\
\hline Netherlands & 1.047 & Slovenia & 1.074 \\
\hline Portugal & 1.042 & Slovakia & 1.192 \\
\hline Spain & 1.069 & & \\
\hline Sweden & 1.055 & & \\
\hline United Kingdom & 1.007 & & \\
\hline
\end{tabular}

unit), the resulting income per an economic unit is greater for equalised than for per capita income. All values in this part are taken from the Eurostat webpage (EUROSTAT).

Table 4 contains the medians of net annual household income per economic unit in 2004-2007. Uniform survey methodology was employed in the whole European Union, allowing a direct comparison of nominal income in different countries. Standard division of the EU countries into three groups (EU27: all present member countries, EU15: the "old" members before 31th December 1995, and EU12: the "new countries") is used first of all. Then all the EU countries are dealt with separately. All values of the medians are in EUR. Particular members of these groups are shown in Table 6.

Tables 5 and 6 represent the average growth rate of the nominal median of incomes of the European Union states in 2004-2007. From Table 4 and Figure 7 we can observe a markedly lower level of nominal income in virtually all former communist countries. Despite this, it is just in the case of these countries that the average growth rate of nominal income is the highest, as we can see from Tables 5 and 6.

In Table 5, the average annual income medians are compared for the above mentioned 


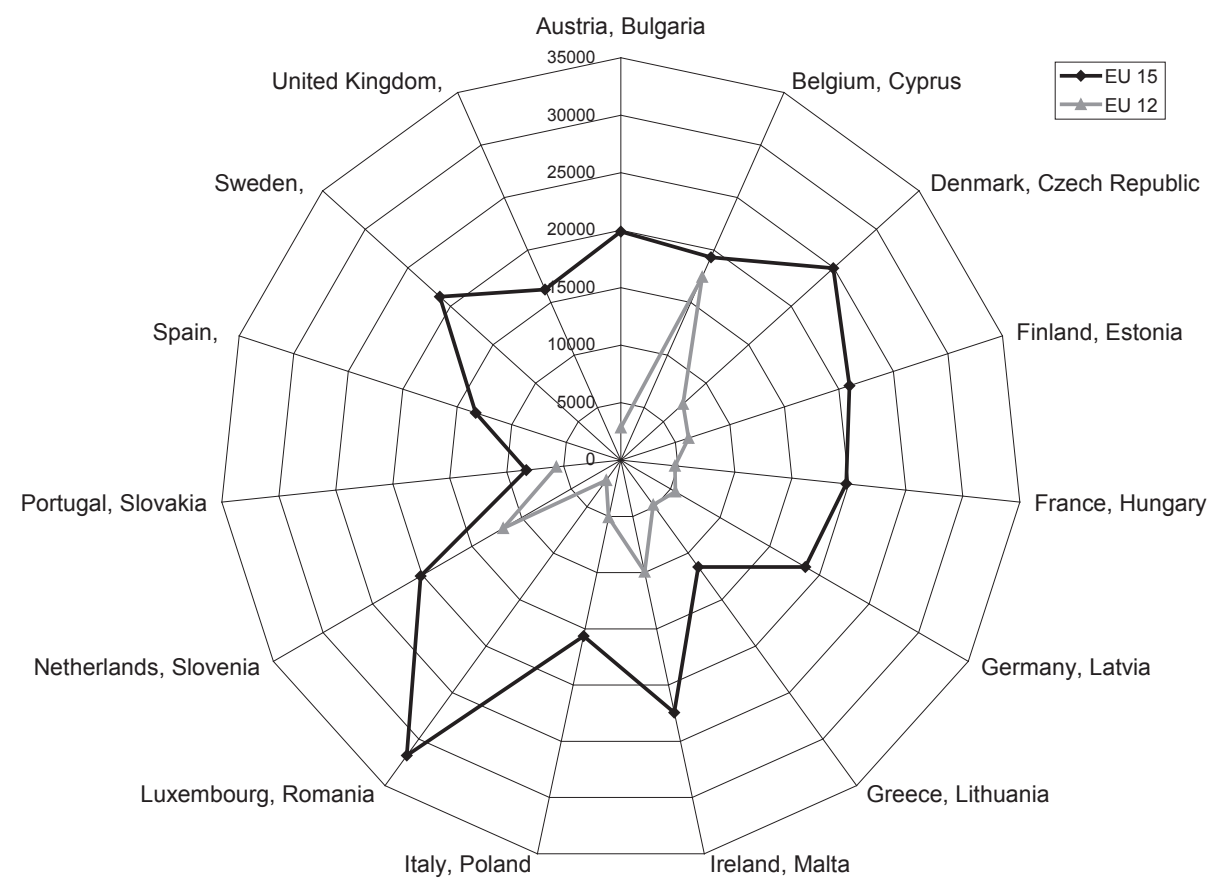

Figure 8: Median of net annual income in 2008 (in EUR).

groups of EU countries and the Czech Republic. Higher values of the rate in the Czech Republic or in the group of "new" countries compared to the "old" EU members are obvious.

In Table 6, the old EU countries are in the left column and the new ones on the right. Again, higher values are apparent for new members with the highest average rate for Bulgaria $(+25.3 \%$ in two years) or Estonia (with $+23 \%)$. Due to the fact that the last year in Tables 5 and 6 is 2007, no effects of the economic crisis are reflected in the statistics.

In Figure 7, the medians of equivalised annual net income are shown for 2008, black triangles indicating the "old" and grey squares the "new" countries. The greater the distance from the centre, the higher the median of income. We can see that the new countries are closer and the old ones further from the centre (with the exception of Cyprus, whose median is comparable to that of old countries), the highest and smallest medians for Luxemburg and Romania respectively being noticeable.

The present paper puts emphasis on the Czech Republic. In Table 7, the medians of both per capita and equivalised incomes for the analysed years (the former taken from our computations, the latter from Eurostat data) are compared. As expected, income per economic unit tends to be greater (it is equal only for one-member households), which is in accordance with higher medians in the second row of the table. The increase in medians of income per economic unit and per capita is $43.3 \%$ and $46.9 \%$, respectively. 
Table 7: Medians of net annual household income (in EUR).

\begin{tabular}{l|cccc}
\hline & \multicolumn{4}{|c}{ Year } \\
& 2004 & 2005 & 2006 & 2007 \\
\hline Net annual per capita income & 3,042 & 3,379 & 3,837 & 4,468 \\
Net annual equivalised income & 4,233 & 4,802 & 5,423 & 6,068 \\
\hline \multicolumn{5}{c}{ Source: Eurostat, CNB, own computations }
\end{tabular}

Table 8: Medians of annual net per capita income in the Czech Republic (in CZK).

\begin{tabular}{l|l|rrrr|c}
\hline & & \multicolumn{4}{|c|}{ Year } & Average \\
& Set & 2004 & 2005 & 2006 & 2007 & growth rate \\
\hline Country & Czech Republic & 97,050 & 100,640 & 108,744 & 117,497 & 1.066 \\
& Bohemia & 98,861 & 102,719 & 110,754 & 119,508 & 1.065 \\
& Moravia & 94,092 & 97,242 & 105,669 & 113,826 & 1.066 \\
\hline Education & Primary & 89,200 & 93,000 & 99,720 & 107,986 & 1.066 \\
& Secondary & 93,374 & 96,000 & 103,500 & 112,508 & 1.064 \\
& Complete secondary & 101,316 & 106,800 & 115,248 & 122,398 & 1.065 \\
& Tertiary & 129,389 & 133,296 & 144,205 & 149,751 & 1.050 \\
\hline Age & $\leq 29$ & 100,120 & 103,881 & 113,470 & 122,503 & 1.070 \\
& $30-39$ & 81,699 & 85,355 & 96,930 & 102,573 & 1.079 \\
& $40-49$ & 95,447 & 95,992 & 103,800 & 111,522 & 1.053 \\
& $50-59$ & 112,100 & 117,209 & 127,625 & 137,984 & 1.072 \\
& $\geq 60$ & 95,800 & 99,600 & 107,185 & 114,800 & 1.062 \\
\hline
\end{tabular}

\section{Conclusions}

In this article, the net annual per capita income is investigated for the period from 1992 to 2007 during which there were the two different states in question - the Czech and Slovak Federal Republic (1992) and the Czech Republic (1993-2007). Sample distributions and their lognormal models are discussed from various points of view.

The three-parameter lognormal distribution was used as a model for incomes, two methods of estimation of the unknown parameters - the maximum likelihood and Lmoment methods - were employed. This approach enables us to compare their accuracy. According to the estimated densities, both methods give similar results, point estimates of parameters, however, being surprisingly different. The obtained level characteristics are also very similar, regardless of the method used.

The worst estimate (measured by standard error) is obtained for the shift parameter $\theta$. It is rather difficult to interpret its values as they are negative for the maximum likelihood method and greater than the minimum value in the sample for the L-moment method.

The appropriateness of the choice of the lognormal as a model was rejected by a $\chi^{2}$ test for all models. But the large-sized sample test power being so high, the test reveals the smallest differences between sample distribution and the model that are neither substantial nor important in practical use. We hope that the distribution is acceptable for the analysis 
as it is frequently used with satisfactory results in the literature dealing with incomes and wages, such a choice being underpinned by relevant theoretical reasons as well (e.g. Gibrat's law of proportionate effects, Kleiber and Kotz, 2003).

The development of distributions and their various characteristics are examined in order to analyse the change of income distributions in the transformation from centrally planned into market economy. It is obvious that income disparities have emerged, a group with markedly high incomes having developed since 1992. The level of income distributions increases distinctively, the skewness of income distributions gradually declining. The amount of net household per capita income depends explicitly on the age and education of the head of household. It can be noted that net per capita income rises with the highest achieved education, but we cannot claim categorically that it rises with the age of the head of household. Households whose head is between 30 and 40 years (maybe with small children) and over 60 years of age (usually those of pensioners) have the lowest net per capita income. Upper and lower bounds determining the net per capita income gap move away from each other in time. During the whole survey period, the obvious growth of annual net per capita income level is registered (in the light of both total and separated sets, according to residence, age and education), a remarkable inflation rate being taken into account. Nominal income was focused on exclusively, its fast growth having been caused by inflation and the real income increase. The nominal income growth was faster than inflation, the real income increase being obvious. This observation is quantified in the text.

Income per capita in $\mathrm{CZK}$ - despite the widespread and recommended use of equivalised income - is analysed in the present research paper. The use of income per economic unit can surpass some strange or surprising results in our analysis and it can ensure better results. At the end, we present medians of equivalised income in EUR for the EU members. European states from the group of 15 original members have a noticeably higher nominal level of income per economic unit, but we can observe a lower growth rate of these incomes. On the other hand, twelve new member states have a substantially lower median of income but higher growth rates.

For the Czech Republic, we compare income per capita with income per unit in Euro in order to illustrate the relation between these two quantities. Different growth rates of median income for the Czech Republic in Euro and CZK may have been caused by the development of the exchange rate of CZK to EUR.

\section{Acknowledgements}

This paper was supported by the means of institutional support of a long-term conceptual advancement of science and research at the Faculty of Informatics and Statistics, University of Economics, Prague, Czech Republic.

\section{References}

Bartošová, J. (2006). Logarithmic-normal model of income distribution in the Czech Republic. Austrian Journal of Statistics, 35, 215-222. 
Bartošová, J., and Bína, V. (2009). Modelling of income distribution of Czech households in years 1996-2005. Acta Oeconomica Pragensia, 17, 3-18.

Bílková, D. (2008). Application of lognormal curves in modeling of wage distributions. In $7^{\text {th }}$ International Conference APLIMAT 2008 (p. 341-351). Bratislava: Slovak University of Technology.

Cohen, A. C., and Whitten, J. B. (1980). Estimation in the three-parameter lognormal distribution. Journal of American Statistical Association, 75, 399-404.

Dagum, C. (1990). Generation and properties of income distribution functions. In Income and wealth distribution, inequality and poverty: Proceedings of the Second International Conference on Income Distribution by Size: Generation, Distribution, Measurement and Applications, University of Pavia, Italy, September 23-30, 1989 (p. 1-17).

Dagum, C. (1997). A systemic approach to the generation of income distribution models. Journal of Income Distribution, 6, 105-126.

Flachaire, E., and Nunez, O. (2007). Estimation of the income distribution and detection of subpopulations: an explanatory model. Computational Statistics and Data Analysis, 51, 3368-3380.

Hosking, J. R. M. (1990). L-moments: Analysis and estimation of distributions using linear combinations of order statistics. Journal of the Royal Statistical Society, Series $B, 52,105-124$.

Hosking, J. R. M., and Wales, J. R. (1997). Regional Frequency Analysis: An Approach Based on L-Moments. New York: Cambridge University Press.

Johnson, N. L., Kotz, S., and Balakrishan, N. (1994). Continuous Univariate Distributions, Volume 1 (2nd ed.). New York: Wiley.

Kleiber, C., and Kotz, S. (2003). Statistical Size Distributions in Economics and Actuarial Sciences. New York: Wiley-Interscience.

Kyselý, J., and Picek, J. (2007). Regional growth curves and improved design value estimates of extreme precipitation events in the Czech Republic. Climate Research, 33, 243-255.

McDonald, J. B. (1984). Some generalized functions for the size distribution of income. Econometrica, 52, 647-665.

Pacáková, V., and Sipková, L. (2007). Generalized lambda distributions of household' incomes. E+M Ekonomie a Management, 10, 98-107.

Parker, S. C. (1997). The distribution of self-employment income in the United Kingdom, 1976-1991. The Economic Journal, 107, 455-466.

Pavelka, R. (2009). Application of density mixture in the probability model construction of wage distributions. Applications of Mathematics and Statistics in Economy: AMSE 2009, Uherské Hradištì, 341-350.

Smithers, J. C., and Schulze, R. E. (2001). A methodology for the estimation of short duration design storms in South Africa using a regional approach based on Lmoments. Journal of Hydrology, 241, 42-52. 
Authors' address:

Diana Bílková and Ivana Malá

Department of Statistics and Probability

Faculty of Informatics and Statistics

University of Economics in Prague

Sq. W. Churchill 1938/4

13067 Prague, Czech Republic

E-Mails: bilkova@vse.cz, malai@vse.cz

Web Page: http://www.vse.cz/ 